\title{
NEGATIVE CAPABILITY: A PHENOMENOLOGICAL STUDY OF LIVED EXPERIENCE AT THE EDGE OF CERTITUDE AND INCERTITUDE
}

\author{
by \\ Dr. Anil Behal *
}

\begin{abstract}
The study examined what it was like for leaders in academia, private practice, and business organizations to be in a state of negative capability during periods of uncertainty and conflict in the workplace. "Negative Capability" is an expression that was coined by the English romantic poet John Keats and suggests a peculiar disposition to stay in mysteries, doubts, and uncertainty without the irritable reaching after fact and reason. Interviews were conducted using the interpretative phenomenological analysis (IPA) methodology. The analysis indicates that the context in which a leader is embedded does not have a significant bearing on how that individual experiences and makes sense of negative capability. The majority of participants interviewed appear to have a diminished capacity to contain uncertainty when faced with paradoxical dilemmas. In such situations, they resort to behaviors such as problem solving, consulting others, shutting down, and dispersing as a means of defending against the uncertainty. An interesting correlation seems to exist between negative capability and obsessive-compulsive disorder (OCD). This warrants future research, and is reported in the final section of the paper under "deviant findings."
\end{abstract}

Keywords: John Keats, interpretative phenomenological analysis (IPA), negative capability, OCD, paradox, levels of abstraction, certainty, uncertainty, dialectics, Zen Buddhism, dispersal, social defenses, reframing.

(C) Dr. Anil Behal (2020). All rights reserved 
* Dr. Behal holds a PhD in Human and Organizational Development and a master's degree in human and Organizational Systems from the Fielding Graduate University, California, USA. His areas of expertise include applied communication theory, phenomenology, and the psychodynamics of organizations. He is the managing director and founder of ORGDYNE Training and Consulting, LLC (http://www.orgdyne.com) and may be reached by email at abehal@email.fielding.edu

Notes:

1. This is a significantly condensed version of a larger body of work that constitutes the author's doctoral dissertation. The latter may be accessed in its entirety at the following URL: http://gradworks.umi.com/36/24/3624967.html

2. Phenomenological studies of this nature are often reported in the first person. The researcher takes a paradoxically bilateral position and is intimately involved in every step of the research, beginning with in-depth interviews with participants, and followed by data collection and analysis.

(C) Dr. Anil Behal (2020). All rights reserved 
(C) Copyright by

DR. ANIL BEHAL

2020

All rights reserved

(C) Dr. Anil Behal (2020). All rights reserved 


\section{Part One \\ Preface}

The danger (of this enterprise), in short is that instead of providing a basis for what already exists, one is forced to advance beyond familiar territory, far from the certainties to which one is accustomed, towards an as yet uncharted land and unforeseeable conclusion. (Foucault, 1972, p. 39)

I first came across the Keatsian expression "negative capability" in a paper by French (2000) in which the author makes important linkages between the poet's aesthetic notion, dispersal, and the containment of emotion. I was so captivated by the phenomenon that I continue to follow it with great curiosity.

Cusa (1440) suggests that as we accumulate knowledge, the darkness of "unlearned ignorance" is diminished; however, the more knowledge we acquire and the more we learn, the greater our awareness of how much we do not know. This new awareness, he refers to as "learned ignorance." I make an analogy between the notion of "unlearned ignorance" and Bion's (1984) formulation of "knowing" which he described using the symbol "K." In direct contrast to the former, Bion conceptualized "O" as the ultimate embodiment of truth that is unknown and unknowable. Bollas (1987) conceptualized this construct as the "unthought known." While the truth-in-the-moment may never enter the realm of knowledge and certitude, Bion believed that it is through the encounter at the edge of knowing and not knowing that we may come under its influence. As Eigen (1998) writes, "It can be creatively explosive, traumatically wounding, crushingly uplifting" (p. 78). As I make sense of my own uncertainty, it seems as though I am lost in reverie, allowing myself to be receptive and yet, perturbed by the experience.

\section{Introduction}

"Negative Capability" is not an expression that is very familiar outside the realm of English literature. Even those who have read Keats may not be particularly conversant with the construct - after all, the poet only used it once in a letter to his brothers in a moment of intense 
speculation. It is a unique capacity for introspection when we are open to thoughts, feelings, and sensation, such that we are able to stay with mysteries, doubts, uncertainties, and ambiguity without the irritable reaching after fact and reason (Keats, 1817).

Simpson and French (2006) posit that attending to the present is a "refrain," a means of avoidance that is both ancient and modern. It implies the ability to live with uncertainty, tolerate frustration, and make room for multiple perspectives that may require a certain degree of patience and passive acceptance. The authors suggest that the practice of negative capability calls upon us to remain in this unsettling mental space in order to face the terrifying pressure of the present where most problems seem to reside. The refrain that they address, is refraining from action. 'In the pressure of the moment, 'what we know' may not be available to us. What we thought we know, or did indeed knew once, can disappear in action when we are 'under fire,' to use Bion's metaphor" (p. 245).

An idea so rich — steeped in the dialectic of predictability and unpredictability captivates my imagination. The predictability arises from the fact that all leaders from time to time are thrust into conditions of uncertainty and perplexity. Ironically though, holding this tension requires a unique state of mind---a peculiar disposition such as negative capability where one is comfortable with doubt, uncertainty, and unpredictability. Batchelor (1990) suggests that "such doubt is neither a cognitive hinge, nor a psychological defect, but a state of existential perplexity" (p. 16).

\section{Research Question}

What is it like for leaders to be in a state of negative capability during periods of uncertainty and conflict in the workplace?

I suggest that negative capability represents a dialectical tension that is virtually endemic to the human condition. We are thrust into these perplexing spaces wittingly and unwittingly. These discursive tensions are evoked in every relationship, regardless of whether it is personal or professional and may be defined as core tensions or opposing values that arise when two seemingly incompatible forces coexist in the mind. Some examples might be the dichotomous relationship between autonomy and connectedness, disclosure and secrecy, and intimacy and abstraction. We seem to oscillate between these values, often unconsciously, and may view them 
as contradictions or internal conflicts. These conflicts may sometimes produce the opposite of what we are trying to accomplish.

\section{Study Objective and Need}

The study was an attempt to understand how leaders experienced the phenomenon of negative capability during periods of uncertainty and conflict in the workplace. They often find themselves in difficult situations such as this, when the pressure to react is strong. Israelstam (2007) suggests that tensions evoked in dialectically charged situations often create new spaces for learning and growth that are related to mindless states. Regardless of whether a leader exercises restraint or decides to take quick action, these tensions may never be truly resolved. My interest in conducting the study was to explore these phenomena in order to shed light on this predicament. While the study was not specifically directed to the lived experience of psychotherapists, it should come as no surprise that in order to practice good therapy, one must have mastery over this unique skill set.

(C) Dr. Anil Behal (2020). All rights reserved 


\section{Part Two}

\section{Literature Review}

Several interrelated theories and paradigmatic frameworks inform the study. These include conversations from the field of organizational psychodynamics (Argyris, 1990; Laiken, 2001, 2002; Raab, 1997) and the work of contemporary theorists who have extrapolated the concept of negative capability to developing a better understanding of servant leadership (Greenleaf, 2008). Additionally, literature from poetry (Keats, 1817), Tibetan and Zen Buddhism (Batchelor, 1990, 2000; Eigen, 1998), and dialogism and dialectics (Bakhtin, 1981; Baxter \& Montgomery, 1996) was reviewed in order to explore the connections between these metatheoretical perspectives and the topic of the study. Elson (2010) contributed to an understanding of levels of abstraction. Johnson's (1992) ideas on polarity management and paradoxical thinking are particularly worthwhile when thinking about negative capability.

This paper is an extrapolation from a much larger body of work that constitutes the author's doctoral dissertation. Given the space limitation, it is not possible to discuss all the theoretical constructs that inform the study, however, in order to provide the reader a deeper understanding of the phenomenon, literature from a primary field of inquiry is reviewed below.

\section{Dialogism and Dialectics}

Dialogism and dialectics are meta-theoretical paradigms and core conversations that inform the study. They address the sophisticated subtleties of negative capability in a way that none of the other paradigms can achieve singularly. While the literature on dialectics does make occasional references to Keats's aesthetic concept (see below), no studies were found that directly address the phenomenon from the standpoint of dialectics.

The origin of dialogism as a philosophical doctrine is attributed to the Russian philosopher Bakhtin (1984), who until recently was best known in literary circles only. It would be fair to say that "dialogism" has not been a part of mainstream social science, and scholars interested in studying interpersonal relationships are only just beginning to reference his work. "Dialectics" has its roots in dialogism, therefore it may be important to understand its meaning and significance. Bakhtin believed dialogue to be the essence of all interpersonal 
communication. Unlike monologue, dialogue is multivocal and characterized by at least two distinct voices.

Bakhtin (1981) writes, "our own discourse is gradually and slowly wrought out of others' words that have been acknowledged and assimilated" (p. 345). He comments about and contrasts dialogic and monologic works. Unlike the latter, Bakhtin believed that dialogic work informs and is informed by previous works. It is an ongoing, bidirectional conversation between language and discourse (both past and present). Bakhtin (1984) further suggests that all meaning making is a dialogue and may be understood literally and metaphorically as a fusion of different systems and discourses. Participants engaged in dialogue must to some extent fuse their perspectives in order to construct a shared meaning. Conversation therefore, is a form of unity of different perspectives, even though participants retain their own unique perspectives on the topic. Multiple perspectives on the same phenomenon, co-constructed by the participants and myself added a richness and depth to the study.

Dialogism has been around for thousands of years in ancient cultures such as China, India, and Japan. It has helped shape these cultures very dramatically, and yet it seems difficult to provide a singular answer or definition of what constitutes dialogism. More contemporary authors such as Altman, Vinsel, and Brown (1981) look at dialogism as having two meanings: (a) a style of reasoning used to establish the truth and validity of ideas, and (b) a worldview or conception of the nature of phenomena. Both are germane to this study, particularly given its phenomenological focus and methodology. It is important here to make a distinction between a dialogic process (Bakhtin, 1984) and a dialectic process (Hegel, 1977, 2003), despite the complementarity of the two constructs:

-Various existential approaches seem to coexist in a dialogic process. It does not have a great deal of rigidity and strategies are open to changes. The outcome is often open-ended and no closure is typically sought.

-In a dialectical process as conceptualized and formulated by Hegel, the goal seems to be to merge point and counterpoint (thesis and antithesis), thereby arriving at a compromise (synthesis). The end result of the process is a desired outcome---a solution that establishes primacy over other alternatives.

In constructing their grand theory of "relational dialectics," Baxter and Montgomery (1996) choose to use the words dialogism and dialectics interchangeably, even though Bakhtin 
and other scholars have made a distinction between the two seemingly alike, but different constructs. They write, “To Bakhtin (1984), the essence of dialogue is its simultaneous differentiation from, yet fusion with another. To enact dialogue, the parties need to fuse their perspectives while maintaining the uniqueness of their individual perspectives" (p. 24). "Just as dialogue is simultaneously unity and difference, Bakhtin (1981) regarded all social processes as the product of 'a contradiction-ridden, tension-filled unity of two embattled tendencies,' the centripetal (i.e. forces of unity) and centrifugal (i.e. forces of difference)" (p. 25). The self may be constituted as a result of the fusion of these forces, that is, the simultaneous need to connect with and separate from the other. It is this interplay between the opposing forces (centripetal and centrifugal), which creates contradiction and difference and brings about a dialectical voice. Bakhtin (1986) was a critic of Hegelian-Marxist dialectics in the following way: "Take a dialogue and remove the voices (the partitioning of voices), remove the intonations (emotional and individualizing ones), carve out abstract concepts and judgments from living words and responses, cram everything into one abstract consciousness---and that's how you get dialectics" (p. 147).

Dialectical tension is produced as a result of the friction between what appear to be contradictory or opposite phenomena. "Hegelian dialectic" is an argument that posits a thesis and antithesis (point-counterpoint), which are then resolved through a synthesis. A dialectical tension can take many forms. As an example, let's take the tension between Blacks and Whites, Christianity and Islam, and public and private. The events that are currently occurring in the Middle East may be a result of dialectical tension.

Baxter and Montgomery (1996) find their own dialectical voice based on the actual and imagined dialogues with scholars such as Bakhtin. They highlight several key themes borrowed from Bakhtin's work on dialogism, from which to formulate their own emerging meaning of social and relational dialectics. "These themes reverberate with Bakhtin's notion of 'dialogue' as enacted communication, 'dialogue' as centripetal—centrifugal flux, 'dialogue' as chronotopic, and 'dialogue' as distinct from 'monologue"' (p. 42).

Baxter and Braithwaite (2008) comment,

The central proposition of "relational dialectics theory" (RDT) is that all of communication is rife with the tension-filled struggle of competing discourses - the discursive oppositions of sociality. An analysis of communication framed by RDT seeks 
to understand this dialectical process by (a) identifying the various discourses that are directly or indirectly invoked in talk to render utterances understandable and legitimate, and (b) asking how those discourses interpenetrate one another in the production of meaning. (pp. 352-353)

In an interesting analysis of the interpenetration of discourses, the authors use the expressions "synchronic" and "diachronic" to describe the emergence of meaning in dialogue. Diachronic means occurring over time, while the former is taken to mean a single moment in time. Even though meanings may appear to be fixed at any given moment in time, they may also be fluid and changing in the next. Participants may jointly reinforce an old meaning or simply construct a brand new meaning in an ongoing process of production or reproduction. The authors believe that it is this interpenetration of competing discourses that constitutes social reality. Bakhtin (writing as Voloshinov, 1973, p. 85) believed that it is not experience that organizes expression, but the other way round-expression organizes experience. The relational dialectics theory (RDT) is unique in that it is the articulation of the "tensionality of difference" as a mechanism that constitutes reality (Baxter, 2006). This process of constitution involves a decentering of the sovereign self that Keats may have referred to in his own way as the annulment of the self. It is through multiple perspectives on the same phenomena, as studied in different contexts, that we may be able to derive meaning through convergence and divergence.

The literature that I have reviewed informs negative capability in some way and points to one thing — being in an ephemeral state of not knowing, ambiguity, and liminality all call for holding and managing dialectical tension over time, and are characterized by different, often contradictory ways of thinking about something. We may experience dialectical tension when our worldview includes two seemingly contradictory (not necessarily dissimilar or unrelated) thoughts, or at least competing ways of thinking about a given topic with no real way to resolve the problem. Some examples of dialectical tension are as follows:

-Group members' struggle between wanting process and content

-Autonomy (abstraction) vs. intimacy

-Togetherness vs. separateness

-Privacy vs. disclosure

(C) Dr. Anil Behal (2020). All rights reserved 
-Introversion vs. extroversion

-Emotion vs. cognition

We are often called upon paradoxically to hold very conflicting and often-painful dialectical tensions that cannot be easily resolved and may leave us emotionally and psychologically paralyzed if left unmanaged. Like a state of liminality, we are not fully vested in either polarity. We are at both ends at the same time. It would be like standing at the edge of the boundary that separates the two positions, and yet fully taking up one position means giving up the other; and what makes this quandary even more difficult is that both positions are somehow interrelated, not mutually exclusive, even though at first they might appear to be.

I see dialectical tension as the common thread that runs through the bodies of literature that I have been discussing, and yet, this tension resides as subtle nuances in each discipline. A practicing Buddhist who is in a state of mindful awareness and reflective inaction might experience the tension differently from an adult learner. A psychoanalyst, who by virtue of training and expertise holds the dialectical tension with a patient, might experience it very differently from a poet or an organizational consultant. I was interested in contextually understanding how these subtle nuances contribute to the lived experience of participants.

In his 1939 monograph on "negative capability," Bate (2012) discusses disinterestedness, passiveness, sympathy, impersonality, and annulment of the self as key elements. While most scholars who are familiar with Keats's literary genius, would support Bate, I have often wondered if there isn't something radically important that has been overlooked in the literature. As an organizational consultant who has done some work with Keats's ideas over the past 10 years, it has been my experience and that of other colleagues whom I have worked with, that negative capability represents a quandary---a rather perturbed and conflicted frame of mind that may be steeped in dialectics.

A search for the expression negative capability on several academic sites, including the Fielding Graduate Institute library of journals and dissertations, returned several pages primarily featuring the work of scholars in organizational psychodynamics and articles critiquing the Keatsian construct in aesthetics. As the search was narrowed to include the expressions "psychoanalysis" and "Buddhism," a plethora of resources was found that make references to the construct. 
As I previously discussed, negative capability is not a mainstream expression that everyone is familiar with. People relate to it in different ways and may think of it as containment, refrain, mindful awareness, reflective inaction, and liminality to name a few. Even Keats, after having used the expression only once, subsequently thought of it as diligent indolence, disinterestedness, annulment of the self, and restless imagination---all of which may suggest an openness to sensation and feeling, the ability to transcend rationality, and the rejection of epistemological bounds.

(C) Dr. Anil Behal (2020). All rights reserved 


\section{Part Three \\ Research Method, Design, and Methodology}

A qualitative research methodology entitled interpretative phenomenological analysis (IPA) was deployed to study negative capability. Given the novelty and innovative nature of the topic, IPA was best suited to study the phenomenon.

Unlike the natural science that studies objects of nature, human science inquiry is about the study of persons or beings that have consciousness. Van Manen, (1990) writes, "Phenomenological research is the study of lived experience. It is seeing the world without taxonomizing, classifying, or abstracting it. It does not test hypotheses or theories, but offers plausible insights" (p. 9).

"Phenomenology" is an attempt to understand the true meaning and essence of experiences as recounted by participants (Heidegger, 1962; Husserl, 1970; van Manen, 2007). In doing phenomenology, one is immersing in the life world of the participants and reliving their experiences or rethinking the actors' thoughts, consistent with the philosophical tradition known as "Verstehen" (Martin, 2000). It also involves setting aside (bracketing) assumptions, biases, and judgments that may otherwise impede the data collection process.

\section{Study Design}

Fourteen leaders were recruited from academia, private practice (self-employed practitioners), and business organizations, following the selection criteria below. None of the participants had previous sentient ties with the researcher. In-depth interviews were conducted on the Go To Meeting web platform and digitally recorded. Examining negative capability from multiple perspectives and contexts added depth and complexity to the study. Smith, Flowers, and Larkin (2009) suggest, "in multi-perspectival studies, the exploration of one phenomenon from multiple perspectives can help the analyst to develop a more detailed and multifaceted account of that phenomenon" (p. 52).

\section{Participant Selection Criteria}

The selection criteria were as follows:

1. Participants should be US residents within the age range of 35-65 
2. Should be currently employed (or self-employed in the case of private practitioners) and have at least 5 years experience at their place of work.

3. Be familiar with the notion of negative capability.

4. Must have experienced significant anxiety at work where they find themselves in a state of uncertainty and conflict.

5. Must be comfortable sharing their experiences with the researcher.

6. Must agree to sign the informed consent form and be willing to have the conversations digitally recorded and shared anonymously in the dissertation and subsequent journal articles and presentations.

\section{Data Collection}

The data gathered during the interviews were personally transcribed and analyzed by the researcher in consultation with the research supervisor. The Inq-Scribe software was used for transcription and analysis.

\section{Data Management}

With each of the four transcript readings, the data collected were coded and recoded by the researcher, then finally coded as a whole in order to identify any emergent themes and patterns. As a reiterative process, it called for checking and rechecking with the participants' accounts to make sure that what was being recorded is what they intended to convey in the interviews. All data were treated with the utmost confidentiality and securely stored.

(C) Dr. Anil Behal (2020). All rights reserved 


\section{Part Four \\ Analysis and Interpretation}

It is important to note that I conducted the analysis by interpreting the text at two levels. Ricoeur (1970) writes about these levels of interpretation, using the expression "hermeneutics" to refer to the theory of interpretation:

1. The "hermeneutics of meaning-recollection," which provides a faithful disclosure of the participants' accounts as they make sense of the phenomenon.

2. The "hermeneutics of suspicion" may involve going below the surface and often behind the phenomenon being studied, in order to understand and interpret its deeper meaning. The researcher conducting this level of analysis tries to make sense of the phenomenon from the participants' accounts, as the participants are making sense of the phenomenon from their own standpoint. This is known as the "double hermeneutic."

\section{Bracketing}

In phenomenological inquiry, the researcher is intimately involved in each aspect of the study, beginning with recruiting and interviewing participants, to thoroughly gathering the data, and final analysis and interpretation. It is a solitary role. Given the complexity of this process, it is anticipated that the researcher's bias and preconceived notions may interfere with the robustness of the approach and integrity of the data collected and analyzed. For this reason, I carefully reflected on and set aside (bracketed) my own paradigmatic framework, assumptions, and familiarity with the negative capability phenomenon so I could study it more objectively. This meant consciously assuming a state of negative capability (refrain) myself, without regard for the doctrinaire of knowledge.

\section{Assumptions}

1. Even though the leaders that I recruited claimed to have a good understanding of 
negative capability, I had some apprehension that they clearly understood the phenomenon, given the obscurity of the construct in everyday life.

2. During various stages of recruitment, I provided a clear definition of negative capability, including an example of what might constitute it. Despite that initiative, I had assumed that leaders might not be able to clearly articulate how they made sense of the phenomenon.

3. After I replaced the negative capability expression with other, more familiar words such as uncertainty, ambiguity, and perplexity in the interview schedule, I suspected that we might end up researching the conditions, rather than the disposition itself.

\section{Group Analysis}

After completing the individual analyses of transcripts from the 14 interviews, the data were then analyzed for the entire group. The interview data are too voluminous to be reproduced here. The analysis was conducted in four steps:

- Listing of the recurring emergent themes, including key phrases and metaphors

- Clustering of group level themes (derived from the previous step)

- Master listing of superordinate themes (extrapolated from the clustering of themes)

- Group narrative

Verbatim extracts from the original transcripts that address the superordinate theme titled "intermingling of personal and professional lives" (see group narrative below) are provided as an example of the kind of data that were analyzed. In part five of this paper under "deviant findings," excerpts from a participant interview (Amanda) are reproduced to illuminate the peculiar relationship of negative capability and obsessive-compulsive disorder (OCD).

\section{Participant Leader 1}

"First of all, I think that no one can truly compartmentalize their personal and professional lives. It may be the noble lie we tell each other, that what happened at home can be separate from work. It's like saying what happened in our childhood would never influence our lives. That is a grand illusion. Everything affects everything else."

\section{Participant Leader 2}

"Absolutely! Not to do with my work, but personal life. I have to deal with mental health issues 
in my family. As you can imagine, with mental health, your best tools don't serve you well. You are dealing with things that your mind cannot rationally determine. Right or wrong are irrelevant. How do you manage yourself in the face of extreme stress? I have most definitely been in situations where there was a great deal of chaos. A great deal of emotion and danger, where my past tools and experiences were in many ways, of little help to me."

\section{Group Narrative}

Several superordinate themes emerged from analysis. Some of the more salient recurring group themes are stated below.

- Exercising servant leadership

- Intermingling of personal and professional life

- Discomfort with managing and holding polarities and paradox (Fig. 1 below is a schematic representation of the theme)

(C) Dr. Anil Behal (2020). All rights reserved 


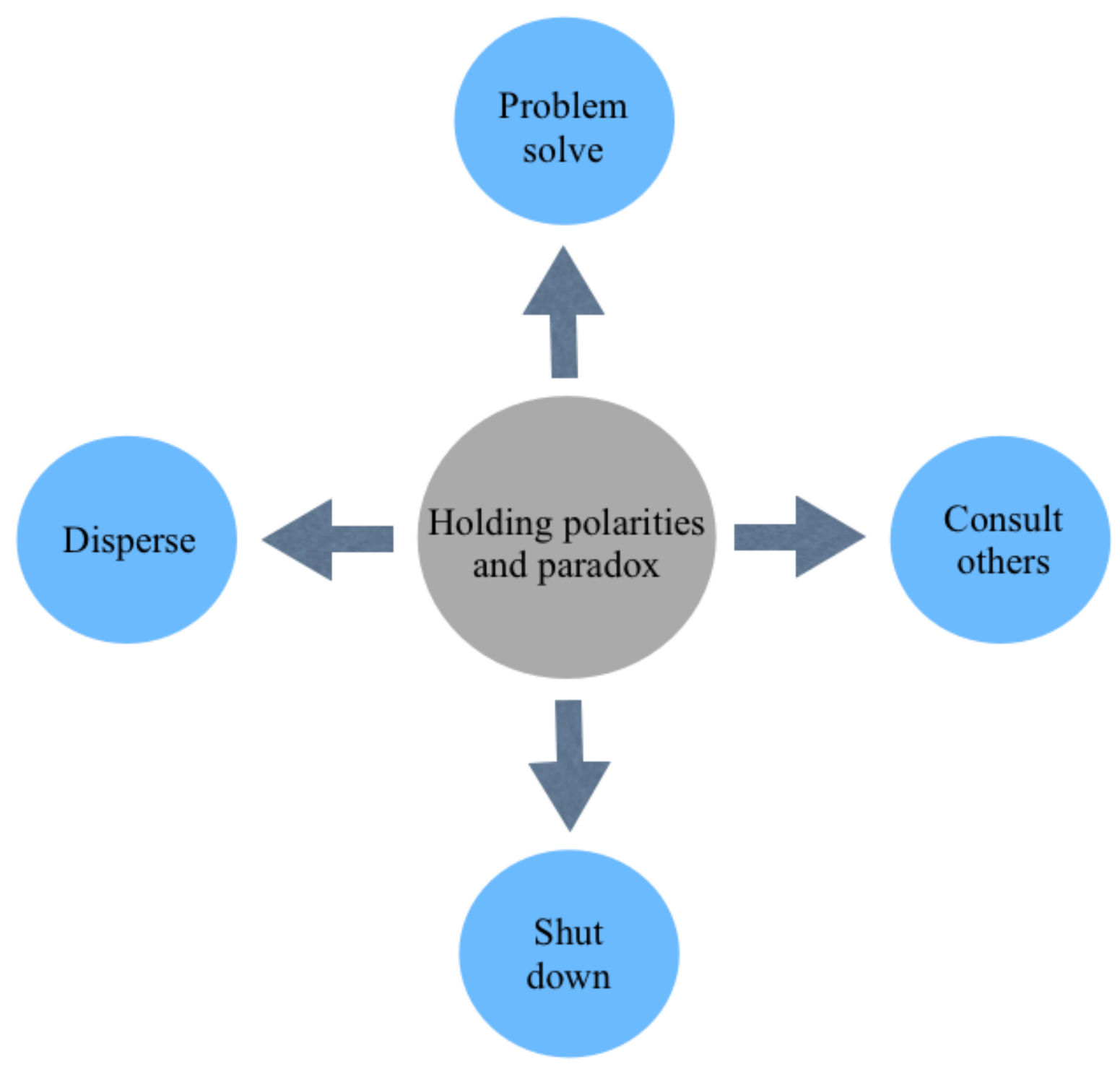

Figure 1. Schematic representation of holding polarities and paradox.

In the interviews, leaders commented that they typically adopted one of four stances when faced with paradoxical dilemmas:

- Go into a problem-solving mode in order to understand the situation.

- Consult confidants at work who may shed light on the situation.

- Emotionally shut down in the face of an impasse where no clear resolution was in sight.

- Disperse into action, which may include engaging in a string of explanations or rationalization in order to break the impasse or bind. If the anxiety becomes too intolerable, the leader may decide to exit the organization. 
This is the most crucial finding of the study. In particular, there seemed to be an inner conflict between how leaders perceived their own style of leading (such as servant leadership) and the manner in which they reacted to conditions such as uncertainty and conflict (by dispersing into action).

It would be fair to say that a servant leader ideally has a highly developed capacity to stay with uncertainty and hold the paradox rather than reacting and fleeing into action when she finds herself in a state of perplexity. This was not found to be true in the majority of interviews, and leads me to believe that the negative capability frame of mind is one that needs cultivation over time. It is not a naturally occurring phenomenon for most leaders. 


\section{Part Five}

\section{Discussion, Findings, Experiences, and Implications}

Leaders are expected to get things done most effectively, most efficiently, and within a designated timeframe. Action therefore takes a higher status than reflection, leaving little or no room for thoughtful meditation and the inclusion of multiple voices and perspectives. I consider this to be a serious challenge facing organizations. Unless this is addressed, important voices will continue to be muted or marginalized, making organizations the perfect ground to breed tension and hostility, both of which are counterproductive.

Batchelor (1990) suggests that there are three factors that need to be cultivated in our quest for new knowledge: great faith, great doubt, and great courage. The "faith to doubt," writes the author, "does not refer to the kind of wavering indecision in which we get stuck, preventing any positive movement. It means to keep alive the perplexity at the heart of our life, to acknowledge that fundamentally we do not know what is going on, to question whatever arises within us" (pp. 16-17). As leaders learn to be more comfortable with doubt and uncertainty, it is hoped that a new cadre of leaders will begin to emerge who can then become trailblazers for others to follow.

\section{Findings}

The outline of individual and group analyses in part four illuminated how leaders made sense of uncertainty and conflict in a variety of ways. They typically chose to deal with perplexing situations rather than sitting and reflecting on them patiently. They became "instruments of action" rather than "instruments of thought."

The analysis indicates three important findings: (a) The context in which leaders are embedded may not have a significant bearing on how they experience and make sense of negative capability, (b) the majority of leaders interviewed appear to have a diminished capacity to contain uncertainty when faced with paradoxical dilemmas, and (c) they resort to behaviors such as problem solving, consulting others, shutting down, and dispersing as a defense against the uncertainty.

As I conducted the in-depth interviews and explored the leaders' workplace interactions, it was interesting to observe the outpouring of highly sensitive personal issues. It seemed to me 
that there was an intermingling of personal and professional issues. I had not expected that the leaders would share issues of a personal nature with a total stranger like myself, especially because the focus of the interviews was the workplace. Is it perhaps possible that when faced with uncertainty, conflict, and perplexity at work, many leaders regress to the comfort of their personal lives as a means of escape and avoidance? Is it also reasonable to expect that their openness and transparency were an outcome of the perceived safety and comfort that they felt with me?

\section{Deviant Finding}

\section{Obsessive Compulsive Disorder (OCD) and Negative Capability}

In participant interview number 1 with Amanda, there was a unique connection established between negative capability and obsessive-compulsive disorder (OCD). While this was not a shared theme among the remaining leaders, I consider it to be worthy of further exploration. In IPA studies, it is not completely unusual to discover something that at first seems to have no relevance to the study phenomenon, and yet, adds significant value to the project. I share this finding here with the hope that it may contribute something worthwhile to the existing body of qualitative literature on OCD. I provide below excerpts from my interview with Amanda.

\section{Case 1: Amanda (private practice)}

Amanda is a highly articulate independent consultant of British origin who lives in the US with her husband and children, and works predominantly with high-end clients in the healthcare industry. She is a certified coach who seems to be greatly influenced by the work, thinking, and methodology of Kegan and associates. Amanda is struggling with serious mental health issues of her two sons, one of whom suffers from chronic obsessive-compulsive disorder (OCD) and the other with a severe form of anxiety. Both sons are grown, but still live with her. While she feels very competent and qualified to handle even the most challenging issues for her professional clients, she feels utterly hopeless, uncertain, and shaky on the home front. Even though Amanda came to the interview extremely composed and confident, the enormous tension that she must feel on account of her personal issues was palpable throughout our conversation.

During the interview, I pursued the linkages between uncertainty, negative capability, and OCD in order to better understand how Amanda made sense of her state of perplexity that seems to have been exacerbated by the hopelessness of her unique situation. As a leader in private 
practice, how does one deal with the ever-present threat and danger of having to confront these huge challenges in one's personal life? Verbatim excerpts from my interview with Amanda follow.

\section{Intermingling of Personal and Professional life}

When asked to talk about a time that she found it particularly hard to determine (make sense of) certain experiences, Amanda commented, "Absolutely! Not to do with my work, but personal life. Wait!!!! I am just going to check if I am in a place in the home where I can speak openly. Wait a moment." (She seemed very guarded and anxious about the situation on her home front). "Okay, so I can. I have to deal with mental health issues in my family. As you can imagine, with mental health, your best tools don't serve you well. You are dealing with things that your mind cannot rationally determine or figure. Right or wrong are irrelevant. How do you manage yourself in the face of extreme stress? I have most definitely been in situations where there was a great deal of chaos. A great deal of emotion...danger, where my past tools and experiences were in many ways, of little help to me."

\section{Obsessive Compulsive Disorder}

Amanda: "So two of my children have had very significant struggle. One was diagnosed with severe OCD. I talked a bit about that when we last spoke. And it's a condition in which the brain gets stuck on certain intrusive thoughts that become rooted. They live with those thoughts and sometimes they come to faulty conclusion that if they do certain rituals they will either manage the anxiety or prevent the feared event from happening. 'My mother is going to die. If I count backward from 100, I can stop it. If I do that, she will be safe.' The secret to getting better is by reframing the fear (it's just the OCD) and enduring it without engaging in the soothing ritual, because the brain then gets habituated to the fear. Every time you perform the ritual to get rid of the anxiety, you actually make it worse in your neural network in the brain until you break the connections."

Amanda: "When they have the thought and don't perform the ritual, there is absolute terror at first. In that space there is absolute terror. It is a life and death situation for them. It's about brain chemistry because if you force yourself to experience the fear and don't perform the ritual, you 
will gradually feel less fear. You will break the faulty connections that say 'If I do X, Y will happen.'... Neurons that fire together, wire together and OCD is a faulty connection you need to break."

\section{Ritualistic Behavior during Uncertainty}

Amanda: "OCD is a doubting condition. You doubt everything. It is only when you embrace doubt integrally that you can free yourself from it." She further commented, "I would not necessarily say it is irrational. It may be irrational from my perspective, not theirs. People are constantly managing their fears...fear of looking stupid, fear of losing relationships, fear of not progressing etc."

\section{Levels of Consciousness (Abstraction) and Work of Kegan (1994)}

Amanda: "So I hesitate using the word OCD about a situation other than a disease. When you know someone who has it, you find the use of OCD for other than disease, insensitive." "There are repetitive behaviors based on narratives just as OCD is based on narratives. A good coach helps them see narratives they have created and then call them into question. So what Kegan would say is that the goal is our foot on the gas, but the things we are protecting ourselves from... whatever they may be... are our foot on the brake. We get stuck. Underneath those fears, we find the stories and when we tease apart the stories that maybe served us in the past, we realize that they may be completely false today."

Amanda: "Going from one level of consciousness to the next is about taking the unconscious and making it conscious. Kegan talks about the socialized mind, self-authoring mind, and self-transforming mind. How little we can really control. Control is such an illusion. We cannot change the uncertainty, but only our attitude toward it. I cannot be like some Buddhists who are able to stay with the uncertainty and accept things without wanting to change them. I want to have an impact."

\section{Managing Polarities}

Amanda is a leader who has a good conceptual understanding of negative capability, and so I directly broached the topic with her and inquired how she made sense of the construct. Her 
response: "It is an approach which is both-and, not either-or. My philosophy of leading is not one thing or another-it is keeping people psychologically safe and holding them accountable. There can be tension there---polarity management. American business used to say you can have cost or quality — not both. The Japanese showed that it was a false dichotomy. Manage the polarities and you can come up with a win-win, both-and solutions. Is negative capability a transient stage? Leaders exist to create results and so leaders need not be paralyzed by not knowing. To be able to acknowledge that they don't know, but perhaps use their past experiences to figure out something that might work and try it out. It is comfort with discomfort!!"

Quite often it is not a matter of taking an either-or approach to solving problems, but rather asking whether the problem is indeed solvable or if it requires holding paradoxes and polarities. Amanda shared in the interview that she does not think that there is a resolution on her home front, as it relates to her sons' illness. She seems to have come to terms with her helplessness. All she can do is continue to hold the tension (see the following theme).

\section{Negative Capability}

Amanda: "Negative capability is called accepting uncertainty_or embracing uncertainty because it is the need to know [certitude] that drives the behavior. And if you can live with doubt when you have OCD, you can get better. I don't know that if I count from 100 backward that my mother would die. Maybe she will, but parents are not comfortable with letting their children struggle and experience anxiety - they are enablers - they clean the entire house with Lysol; they act as though they themselves have OCD. The importance of not enabling is central-it is absolutely central. Every time you create an illusory safety, you are playing into the problem by running away from uncertainty and not knowing."

In order to better understand the correlation of negative capability and OCD, I paraphrase Keats' definition. "Negative Capability is the capacity to remain in mysteries, doubts, and uncertainty without the irritable reaching after fact and reason." Remaining in mysteries, doubts, and uncertainty for any length of time is not easy. OCD is a chronic "doubting condition," one in which the sufferer is overwhelmed by recurring and intrusive thoughts. As Amanda (case 1) shared: "There is absolute terror in that space. There will be explosive behavior if you get between the thought and the ritual." As the patient's anxiety is heightened, so is the impulse to 
alleviate it by performing a ritual. While performing the ritual is a patient's defense mechanism for managing and containing the anxiety, it serves to both alleviate and perpetuate it. The key would be to help the patient break the linkage between a thought and a ritual. Not performing a ritual would be tantamount to resisting the impulse to reach out with action, fact, and reason. It is hoped that this initiative may help alleviate the suffering of those who are afflicted with moderate to severe OCD.

\section{Experiences and Continuing Research}

In addition to the findings, I would like to share other experiences. As I undertook the study, I had speculated that negative capability was an ephemeral state of mind that may easily give way to an overwhelming need for certitude. I had also hoped, on the other hand that there would be some leaders that could potentially stay in a reflective mindset while resisting the temptation to engage in dispersal. Clearly, that has not been the outcome of the study in all three contexts. It seemed as though leaders tried to make sense of the phenomenon as it related to their emotional and psychological conditions such as uncertainty, doubt, ambiguity, and perplexity, but found it difficult to relate those conditions to negative capability as a frame of mind.

In future studies of a phenomenological nature, especially those involving the research of an abstract phenomenon such as negative capability, it may be helpful to invest more time into recruiting a more purposive sample. It is not sufficient to take participants' assurances for granted that they comprehend the research topic. They must also demonstrate their understanding of it. Perhaps, they should be required to answer a short questionnaire or respond to a case scenario before they are finally selected.

I am entertaining the notion of conducting a further study on negative capability in the future, solely with participants who come from a psychotherapeutic background. My reasoning for this is that therapists, by virtue of their training and expertise, would perhaps have a deeper understanding of the complexities involved. Consequently, they may be able to shed more light on this intriguing phenomenon.

\section{Negative Capability and Team Creativity}

I am wondering if negative capability is an "internal constraint" or a "transformative

mindset." Based on the study, one could reason that the phenomenon could be examined either 
way. On the one hand, it creates a great deal of anxiety, which as we have seen, may be defended against by actions that seem to alleviate the pressure that a leader feels. By taking action, the leader rids herself of that tension and escapes the quandary. On the other hand though, leaders that have cultivated the capacity to stay in mysteries, doubts, and uncertainties without the irritable reaching after fact and reason, may successfully create and negotiate an environment in which transformations may occur.

Is it possible that highly creative people working in teams can manage internal and external constraints while remaining true to teamwork? The study indicates that contrary to the commonly held belief that internal and external constraints impede creativity and transformation in groups, the reverse can be true. Internal constraints such as negative capability may help catalyze creativity by thrusting team members in a state of not knowing. It provokes them to think, reflect, and find new ways of being. On the other hand, external pressures such as deadlines, limited resources, and emphasis on metrics do not suppressive creativity. They may actually enhance it.

\section{Redefining Negative Capability: Final Thoughts}

This study is important because an increasing number of professions demand that leaders be able to deploy negative capability as part of their jobs. The construct is fascinating, but when it comes to practice, people seem to find it challenging. There may be a need to develop a postmodern definition of negative capability that is more pragmatic and realistic for our times.

The practice of negative capability presents a strange paradox as we attempt to hold two contrasting and conflicting attitudes together, resulting in a state of tension. What makes the predicament even harder is that the two positions (polarities) may not necessarily present us with an easy choice (either-or). They very often are complementary and interdependent, not mutually exclusive. And yet, the creative tension that we speak of is a result of contradiction, which is necessary for discourse and dialogue. While homogeneity and consensus are congenial, contradiction and difference, on the other hand can be terrifying.

Research scholars, especially those that are engaged in qualitative studies, may find that the practice of negative capability may provide a means of holding their anxieties and tensions in what can be a very messy process that is replete with uncertainty. Denzin and Lincoln (1994) write, "The field of qualitative research is defined by a series of tensions, contradictions, and hesitations" (Denzin \& Lincoln, 1994, p. 15). On the one hand, a researcher with a post- 
positivist mindset who takes a detached, hands-off approach in the interview may create more objective space, but on the other hand, the individual may also be viewed as disinterested and distant. So how does one hold this difficult dialectic?

Glesne and Peshkin (1992) suggest that a successful researcher is one who can remain "paradoxically bilateral" (dominant, but also submissive). Oakley (1981), a feminist researcher contends that the goal in most interviews is best achieved when the interviewers and interviewees are in a nonhierarchical relationship, with the former willing to invest their personal identities in the relationship. I made an attempt in this study to remain paradoxically bilateral--subjective and objective at the same time. The study was full of challenges and contradiction, and yet, it was in the very nature of the inquiry that I discovered new insights. I would not have been able to engage in the study if I could not practice negative capability myself. Scholars with a positivist mindset, entering qualitative research for the first time, may do well to cultivate a negative capability frame of mind.

Being in a negative capability mindset is like undertaking a journey without a clear destination. Phenomenologists are called upon to constantly work in liminal spaces. Bentz and Rehorick (2008), using the metaphor of a wild horse to describe the final stage in hermeneutic phenomenology write, "In level 3, one rides the wild horse, taking the risk of ending up in a place one did not expect. One lets the horse become the guide" (p. 21).

It may be that in contemporary times, staying in the present without regressing to the past or fleeing into the future is all that we can learn to do. Attending experiential conferences in the Tavistock tradition is a unique way to cultivate a "here-and-now" awareness that may build the capacity to contain perplexing experiences and stay with the present. It provides an opportunity for members to experience what it is like to face and make sense of anxiety. Such experiences bring us face-to-face with unconscious and tacit processes that are pervasive in groups.

Nearly 200 years after its coinage by a romantic poet in his early 20s, negative capability continues to be raised by scholars to a canonical status. There is no finality, and if I were to put a definition around something so elusive, I am indulging in the pursuit of knowledge, as opposed to staying with the not knowing. If I profess to know all that there is to know about negative capability, I will have failed miserably in this endeavor. What I hope I have tried to do is engage 
the reader's questioning mind. Batchelor (1990) suggests that where there is great questioning, there is great awakening. Where there is little questioning, there is little awakening. Where there is no questioning, there is no awakening.

Understanding that the void of "not knowing" is the womb for new creations and breakthroughs, is perhaps a powerful enough awareness that may lead to change and transformation in society. It is my hope that many courageous leaders will continue on that journey and set an example for others who are too anxious or fearful to embark on that path.

(C) Dr. Anil Behal (2020). All rights reserved 


\section{References}

Altman, I., Vinsel, A., \& Brown, B. (1981). Dialectic conceptions in social psychology: An application to social penetration and privacy regulation. In L. Berkowitz (Ed). Advances in experimental social psychology (Vol. 14, pp. 107-160). NY: Academic Press.

Argyris, C. (1990). Overcoming organizational defenses. NJ: Prentice Hall.

Bakhtin, M.M. (1981). The dialogic imagination. Austin: University of Texas Press.

Bakhtin, M.M. (1984). Problems of Dostoevsky's poetics (C. Emerson, Ed. \& Trans.). Minneapolis: University of Minnesota Press.

Bakhtin, M.M. (1986). Speech genres and other late essays. (C. Emerson \& M. Holquist, Eds; V. McGee, Trans.). Austin; University of Texas Press.

Batchelor, S. (1990). The faith to doubt: Glimpses of Buddhist uncertainty. Berkeley, CA: Parallax Press.

Batchelor, S. (2000). Verses from the center: A Buddhist vision of the sublime. New York: Riverhead Books.

Batchelor, S. (2000). Negative capability, emptiness, Nagarjuna, and Keats. Podcast of lecture delivered at the Trinity College, CT on April 11, 2000. Retrieved July 17, 2013 from http://www.radio4all.net/index.php/program/1817

Bate, W.J. (2012). Negative capability: The intuitive approach in Keats. NY: Contra Mundum Press.

Baxter, L.A., \& Montgomery, B.M. (1996). Relating: Dialogues and dialectics. New York, NY: Guilford Press.

Baxter, L.A. (2006). Communication as dialogue. In G.J. Shepherd, J. St. John \& T. Striphas (Eds.). Communication as perspectives on theory. (pp. 101-109). Thousand Oaks, CA: Sage

Baxter, L.A. \& Braithwaite, D.O. (Eds.). (2008). Engaging theories in interpersonal communication. Thousand Oaks, CA: Sage.

Bentz, V.M., \& Rehorick, D.A. (2008). Transformative phenomenology. New York, NY: Lexington Books.

Bion, W.R. (1984). Attention and interpretation. London, UK: Karnac. 
Bollas, C. (1987). The shadow of the object: Psychoanalysis of the unthought known. New York, NY: Columbia University Press.

Cusa, N. (1440). Learned ignorance (publisher unknown)

Czander, W.M. (1993). The psychodynamics of work and organization. New York, NY:; The Guilford Press.

Denzin, N.K. \& Lincoln, U.S. (Eds.). (1994). Handbook of qualitative research. Thousand Oaks, CA: Sage.

Eigen, M. (1998). The psychoanalytic mystique. London, UK: Free Association Books.

Elson, L.G. (2010). Paradox lost: A cross-contextual definition of levels of abstraction. Cresskill, NJ: Hampton Press.

Foucault, M. (1972). The archaeology of knowledge. London, UK: Tavistock.

French, R. (2000, summer). Negative capability, dispersal and the containment of emotion. Bristol Business School Teaching and Research Review, 3.

Glesne, C. \& Peshkin, A. (1992). Becoming qualitative researchers: An introduction. New York, NY: Longman.

Greenleaf, R.K. (2008). The servant as leader. Westfield, IN: The Greenleaf Center for Servant Leadership.

Heidegger, M. (1962). Being and time. Oxford, UK: Blackwell.

Husserl, E. (1970). The crisis of European sciences and transcendental phenomenology. (Trans. D. Carr, Trans.). Evanston, IL: Northwestern University Press.

Israelstam, K.V. (2007). Creativity and dialectical phenomena: From dialectical edge to dialectical space. International Journal of Psychoanalysis, 88, 59-607.

Johnson, B. (1992). Polarity management: Identifying and managing unsolvable problems. Amherst, MA: HRD Press.

Keats, J. (1817). The letters of John Keats, 1814-1821 (2 Vols.) (H. E. Rollins, Ed.). Cambridge, MA: Harvard University Press.

Laiken, M.E. (2001). Models of organizational learning: Paradoxes and best practices in the postindustrial workplace. In C. Rarick (Ed.), Conference Proceedings of the $21_{\mathrm{st}}$ OD World Congress. (pp. 1-16). Vienna, Austria: July 16-21, 2001.

Laiken, M.E. (2002). Managing the action/reflection polarity through dialogue: A path to transformative learning. (NALL Working Paper \#53). Toronto, ON: NALL

(C) Dr. Anil Behal (2020). All rights reserved 
Martin, M. (2000). The uses of understanding in social science: Verstehen. Edison, NJ:

Transaction.

Oakley, A. (1981). Interviewing women: A contradiction in terms. In H. Roberts (Ed.), Doing feminist research. (30-61). London, UK: Routledge \& Kegan Paul.

Phillipson, S. (2014). Obsessional thinking. In Anxiety Care UK. Retrieved February 26, 2014 from http://www.anxietycare.org.uk/docs/obsessionalthinkingonline.asp

Raab, N. (1997). Becoming an expert in knowing: Reframing teacher as consultant. Management Learning, 28(2), 161-175

Ricoeur, P. (1970). Freud and philosophy: An essay on interpretation. New Haven: Yale University Press

Simpson, P., \& French, R. (2006). Negative capability and the capacity to think in the present moment: Some implications for leadership practice. Leadership, 2, 245. DOI: $10.1177 / 1742715006062937$

Smith, J.A., Flowers, P., \& Larkin, M. (2009). Interpretative phenomenological analysis: Theory, method and research. London, UK: Sage.

Van Manen, M. (1990). Researching lived experience: Human science for an action sensitive pedagogy. Albany: State University of New York Press.

Van Manen, M. (2007). Phenomenology of practice. Phenomenology \& Practice, 1(1), 11.

Voloshinov, V.N. (1973). Marxism and the philosophy of language (L. Matejka \& I.R. Titunik, Trans.). Cambridge, MA: Harvard University Press.

(C) Dr. Anil Behal (2020). All rights reserved 
(C) Dr. Anil Behal (2020). All rights reserved 